LBL -31864

DE93 001573

\title{
RADON ENTRY INTO BASEMENTS: APPROACH, EXPERIMENTAL STRUCTURES, AND INSTRUMENTATION OF THE SMALL STRUCTURES RESEARCH PROJECT
}

\author{
W.J. Fisk, M. P. Modera, R.G. Sextro, K. Garbesi, H.A. Wollenberg \\ T.N. Narasimhan, T. Nuzum, Y.W. Tsang
}

February 1992

\author{
Indoor Environment Program \\ Applied Science Division \\ and \\ Earth Sciences Division \\ Lawrence Berkeley Laboratory \\ 1 Cyclotron Road \\ Berkeley, California 94720
}

This work was supported by the Director, Office of Energy Research, Office of Health and Environmental Research, Environmental Sciences Division and by the Assistant Secretary for Conservation and Renewable Energy, Office of Building Technologies, Building Systems and Materials Division of the U.S. Department of Energy (DOE) under Contract DE-AC03-76SF00098.

\section{MASTER}




\section{ABSTRACT}

We describe the experimental approach, structures, and instrumentation of a research project on radon generation and transport in soil and entry into basements. The overall approach is to construct small precisely-fabricated basements in areas of different geology and climate, to control the pressures and ventilation rates in the structures, and to monitor radon concentrations and other relevant parameters over a period of one year or more. Two nearly air-tight structures have been constructed at the first site. The floor of each structure contains adjustable-width slots that serve as the only significant pathway for advective entry of radon. A layer of gravel underlays the floor of one structure; otherwise they are identical. The structures are instrumented for continuous or periodic monitoring of soil, structural, and meteorological parameters that affect radon entry. The pressure difference that drives advective radon entry can be maintained constant or varied over time. Soil gas and radon entry rates and associated parameters, such as soil gas pressures and radon concentrations, have been monitored for a range of steady-state and time-varying pressure differences between the interior of the structure and the soil. Examples of the experimentally-measured pressure and permeability fields in the soil around a structure are presented and discussed.

\section{INTRODUCTION}

The surrounding soil is usually the dominant source of radon $\left({ }^{222} \mathrm{R} n\right)$ in buildings with even moderately elevated radon concentrations (Nazaroff and Nero 1988). Radon is produced within the soil by the radioactive decay of radium and is transported through soil by molecular diffusion and the advective (pressure-driven) flow of soil gas. Pressure-driven flow of soil gas into structures, through cracks, joints, and holes that extend between indoors and the soil, is considered to be the dominant process of radon entry into most buildings with moderate or high radon concentrations. The few Pascal pressure differences that drive this entry result primarily from the reduced density of heated indoor air relative to the density of outdoor air (i.e., the stack effect), wind, and mechanical systems, such as exhaust fans, that cause a net flow of air to outdoors. According to model predictions (Narasimhan et al. 1990, Tsang and Narasimhan 1991), radon entry can also be driven by fluctuating barometric pressure.

The process of radon entry into houses with basements has previously been investigated experimentally, in part, by long-term monitoring of numerous parameters in occupied houses (see, for example, Turk et al. 1990 and Dudney et al. 1989). Parameters monitored include radon concentrations indoors and in the soil, soil permeability, pressure differences, indoor temperatures, furnace operation, and outdoor environmental conditions. Some of these field studies included analyses of the radon sources, including the radium content of soil samples, the radon exhalation rate from building materials, and the concentrations of radon in the domestic water supply. Although much valuable information has been obtained through these studies, they have not provided data suitable for fully developing and validating theories and models of radon entry. Some important information is not readily obtainable in field studies of existing houses. Examples of such information are the nature and location of penetrations in the basement substructure that connect to the soil and the permeability of backfill and aggregate adjacent to the exterior surfaces of basements. In addition, experimental manipulation of the driving forces for radon entry and installation of large numbers of probes within the soil are not practical at the site of occupied houses.

Radon entry processes have also been investigated through the development and use of models (primarily numerical models) of soil gas and radon transport. Early numerical modeling includes that by Scott (1983), Eaton and Scott (1984), 
DSMA (1985), Dimbylow (1987), Loureiro (1987), and Mowris and Fisk (1988). These carly models do not account for many potentially important factors such as the spatial variability of critical soil properties, transient flow, and the impact of buoyancy forces on flow. In addition, as stated previously, these models have not been validated.

\section{RESEARCH APPROACH AND STATUS}

To substantially advance our understanding of radon transport in soil and entry into basements, an interdisciplinary research project, called the "Small Structures Project", with complementary experimental and modeling components, was initiated in 1988. Fisk et al. (1989) provide an early status report on this research project. Specific objectives include determinations of the mechanisms of radon entry and the dependence of radon entry on: (1) soil characteristics including soil permeability, radium content, radon emanation, soil moisture, and heterogeneity; (2) building characteristics including the size and location of penetrations to the soil and the presence of subslab aggregate; (3) steady-state and time-varying indoor-outdoor pressure differences caused by a variety of factors; and (4) climatic/environmental factors such as precipitation and barometric pressure changes. Project objectives also include the development and validation of advanced models of radon entry.

The basic experimental approach is to monitor the rate of radon entry into small (6.4 $\mathrm{m}^{2}$ floor area) precisely-fabricated basements (called small structures). The soil surrounding the structures is sufficiently permeable for appreciable advective soil gas and radon entry. The soil is extensively characterized. Relevant temporallyvariable characteristics of the soil, structure, and climate are simultaneously monitored. The pressure differences that drive radon entry, the structure ventilation rate, and the size and locations of openings between the interior of the structure and the soil are controlled. By intentionally varying certain experimental conditions, such as the magnitude of applied depressurization or the size and location of openings to the soil, we can study the impact of these conditions on the radon entry rate and on the coincident pressure fields and radon concentrations within the soil. Repeating experiments at different times of year, permits us to track naturally varying parameters, such as soil moisture and permeability, and to determine the impact of these parameters on radon entry rates. The future construction of similar structures at different sites will permit us to examine the influence of geology and climate on radon entry.

Numerical modeling complements the experiments. The approach is to upgrade and validate both steady-state and transient models of soil gas and radon transport. Model predictions advance our understanding of the significance of different mechanisms of radon entry and indicate the influence of various geologic, building and climatic factors on entry rates. An interactive process of modeling and experimentation provides data for evaluating the models and also yields model predictions that serve to guide the experimentation.

The status of research within this project is as follows. The first site has been selected and characterized. The site is located at $790 \mathrm{~m}$ elevation on the top of a broad ridge in the Santa Cruz Mountains approximately 10 miles north of the city of Santa Cruz (Wollenberg et al. 1990). The soil is a residual sandy loam developed from weathered quartz diorite (Leo 1967, Bowman and Estrada 1980). Soil permeability ranges spatially between approximately $10^{-13} \mathrm{~m}^{2}$ and $10^{-11} \mathrm{~m}^{2}$. Radium concentrations range between 30 and $40 \mathrm{~Bq} / \mathrm{kg}$. Flexser and Wollenberg (1992) describe the selection and characterization of the site and present an approach for determining the location of uranium in soil grains, which, in turn, affects the amount of radon that emanates from the sites of radium into the pore spaces between soil grains. At this site, we have constructed two small structures, which are identical except for the presence (or absence) of a layer of aggregate beneath the concrete slab floor. The instrumentation system for one structure is complete and experiments have been underway for 
approximately one year with interruptions as required to correct problems or add capabilities. We are currently fabricating the instrumentation system for the second structure.

Numerical modeling has preceded the collection of associated experimental data. The steady-state numerical model is described in detail by Revzan et al. (1991). This paper also provides an initial assessment of the impact of buoyancy forces, caused by heat loss from the basement, on radon entry. Revzan and Fisk (1990) and Revzan et al. (1991b) describe numerical predictions of the influence of structural factors on radon entry into houses with basements and houses with a particular type of slab-on-grade floor, respectively. Narasimhan et al. (1990) and Tsang and Narasimhan (1991) describe modeling of transient soil gas and radon entry into basements, driven by atmospheric pressure fluctuations with amplitudes of tens of Pascals and various periods. These papers indicate that transient radon entry is important in some situations. The remainder of the present paper focuses on a description of the structures, instrumentation, and experimental procedures. Examples of the experimental data are presented and discussed. In a companion paper, Garbesi et al. (1992) describe the results of the initial experimental investigation of steadystate soil gas transport driven by a steady pressure difference, compare the experimental results to predictions of a steady-state numerical model, and discuss possible explanations for the substantial discrepancy between measured data and predictions.

\section{STRUCTURE DESIGN AND CONSTRUCTION}

\section{Design Objectives}

A major objective was to construct very precise structures so that uncontrolled structural features would not prevent accurate assessments of the effects of site-specific variables, such as soil properties, on radon entry. Consequently, we required precise control of the size and location of openings between the interior of the basements and the soil as well as a well-defined structure geometry. Extremely air-tight structures were also required. Air tightness is quantified by the effective leakage area (Sherman 1985) which is the area of a single leakage path between indoors and outdoors that has the same resistance to air flow as all actual leakage paths. Structures with less than $2 \mathrm{~cm}^{2}$ total effective leakage area were required for two reasons. First, a small effective leakage area limits the rate of air leakage between the structure and outdoors, so that the structure ventilation rate is readily controlled and measured using a small mechanical ventilation system with mass flow controllers. Second, the small leakage area permits indoor pressure control by mechanically supplying and withdrawing air at moderate but different flow rates. To simplify monitoring of backfill properties and the associated modeling, design objectives also included homogeneous soil in the backfill zone adjacent to the basement walls, with a permeability similar to that of the in-situ soil. Finally, because models indicate that the permeability of the soil or other material (e.g., aggregate) immediately adjacent to the exterior surfaces of the substructure has a large influence on the rate of soil gas entry, we required minimal compaction (during construction) of the existing soil beneath the basement floor and fabrication of two structures, one with and one without aggregate beneath this floor.

\section{Description of Structures}

A diagram of a cross section of a structure is provided in Figure 1. The basement floor dimensions are $3.2 \mathrm{~m}$ by $2.0 \mathrm{~m}$ and the ceiling height is $2.1 \mathrm{~m}$. The reinforced concrete floor and footing was fabricated (i.e., the concrete poured) at the site as a single unit. The installation of a prefabricated floor-footing system in the excavation was considered; however, we suspected that such a construction process would yield an atypical interface with the soil, with gaps due to an imperfect fit to the excavation. 
Typical basement design and construction results in a shrinkage gap between the floor slab, footing, and basement walls as well as openings around pipes and conduits that extend into the soil. However, these openings are not readily reproducible and are very difficult to characterize. These unintentional openings have been minimized by sealing the base of a prefabricated, one-piece, concrete wall system, consisting of the four walls, into a keyway formed in the top of the onepiece floor-footing unit. The junction between the walls and the floor-footing unit is sealed with a grout that expands slightly during hardening and with a urethane sealant. The exterior surfaces of the walls were sealed (water-proofed) with a polyurethane coating. To approximately simulate a typical shrinkage gap, the concrete floor slab contains six openings to the soil $1.0 \mathrm{~m}$ long and $0.07 \mathrm{~m}$ wide approximately $0.35 \mathrm{~m}$ from the periphery of the floor. Adjustable-width slots that provide openings to the soil are sealed into these openings. The lower edges of the slots contact the subslab soil or aggregate. The slots consist of pairs of precision (i.e., very flat) aluminum plates separated by precision shims, bolted together, and sealed into the openings through the slab floor. Using different sets of shims, the plate spacing (slot width) can be $0.13 \mathrm{~mm}, 0.64 \mathrm{~mm}, 3.2 \mathrm{~mm}$, and $12.7 \mathrm{~mm}$ with a tolerance of approximately $0.03 \mathrm{~mm}$ at the smallest spacing and $0.1 \mathrm{~mm}$ at larger spacings. The assemblies of plates are sealed into the openings using a combination of flexible foam rod, duct seal, and a flowable urethane sealant designed to adhere to concrete. Laboratory tests confirmed that there is negligible leakage through this type of seal. Using a test stand in the laboratory, the relationship between flow through the slots and pressure drop has been measured. As shown in Figure 2, for slot widths of 0.13 $\mathrm{mm}$ and $0.64 \mathrm{~mm}$, the measured pressure drops coincide with theoretical predictions within seven percent. With the slot width of $3.18 \mathrm{~mm}$ (data not shown), the pressure drops are too small $(0.5$ to $3.5 \mathrm{~Pa})$ for highly accurate measurements and the measured pressure drops exceed predictions by as much as $35 \%$. However, with such a wide slot, the pressure drop across the slot will be negligible compared to the drop in pressure in the soil (Mowris and Fisk 1988).

The roof is fabricated from two sheets of aluminum welded together and reinforced with aluminum channel on its exterior surface yielding a smooth interior surface that is easily sealed to the top of the walls. A gasket is installed between the top of the walls and the aluminum roof and this junction is also closed with a sealant. Water that collects on the roof is directed away from the structure through flexible plastic pipe. An access hatch is installed in the roof. Tests of air leakage between the interior of the structure and outdoors (with the slots sealed) using the method of Sherman (1985) yielded a total effective leakage area of $0.24 \mathrm{~cm}^{2}$.

A trailer adjacent to the structures houses most of the instrumentation. Two electrical conduits, buried slightly below grade, connect the interior of each structure to the trailer. These conduits contain wires for instrumentation and electrical power, tubing for structure ventilation and pressure control, and tubing connected to the soil probes. The conduits are sealed at the basement end. High-voltage wiring for power and low-voltage signal wiring for instruments are directed through different conduits to prevent electrical interference.

The soil walls of the excavation were vertical and supported by shoring during construction. The region between the exterior surfaces of the concrete basement walls and the surfaces of the excavation (backfill zone width of $0.7 \mathrm{~m}$ to $0.9 \mathrm{~m}$ ) was backfilled with a blend of the excavated soil. To control the backfill properties, the blend of excavated soil was emplaced in approximately $0.3 \mathrm{~m}$ thick layers and compacted mechanically. Compaction was monitored and controlled by use of gamma-ray and neutron measurements of density and moisture content, respectively. Based on 26 field measurements, the dry density of the backfill averages $1400( \pm 50) \mathrm{kg} / \mathrm{m}^{3}$ [ \pm one standard deviation] and the relative compaction of the backfill, with respect to maximum dry density, is $84(+3) \%$. Multipoint measurements on numerous occasions indicate that the backfill permeability varies spatially over a range of approximately six.

We specified a subslab gravel layer with a uniform $0.1 \mathrm{~m}$ thickness for the 
structure with subslab aggregate; however, based on measurements of gravel thickness where probes penetrate through the slab floor, the thickness ranges from $0.06 \mathrm{~m}$ to $0.2 \mathrm{~m}$. Fortunately, our numerical modeling indicates that variations in gravel thickness over an even larger range $(0.01 \mathrm{~m}$ to $0.3 \mathrm{~m})$ affect the radon entry rate by only $20 \%$ when the soil permeability is $10^{-11} \mathrm{~m}^{2}$ (Revzan and Fisk 1990). To prevent concrete from filling any of the interstitial spaces within the aggregate or seeping into the surface of the soil (for the basement without sub-slab gravel) and to conform with typical construction practice, a polyethylene membrane was placed on the upper surface of the sub-slab gravel or soil prior to pouring the concrete. After construction, the membrane was removed at the bottom of each opening for a slot.

\section{Gravel Permeability}

The permeability of the gravel emplaced beneath the slab floor of one structure was measured in the laboratory. To perform the measurement, a vertical 3.7 $m$ long section of plastic pipe with an internal diameter of $0.10 \mathrm{~m}$ was filled with a sample of this gravel (called $3 / 8$ inch pea gravel). Air was forced through the column of gravel at several flow rates whi'e measuring the flow rate using a dry test meter with an estimated accuracy of $\pm 3 \%$. The pressure difference between the two ends of the column was measured using an electronic micromanometer with an estimated accuracy of $\pm 0.5 \mathrm{~Pa}$. The resulting relationship between pressure drop per unit length and air velocity is shown in Figure 3. Based on the figure, the relationship is nearly linear for the lowest three velocities. A linear relationship between velocity and pressure drop is indicative of Darcy flow (see Scheidegger 1960), thus, the permeability $(k)$ was calculated using a rearranged version of Darcy's Law

$$
k=V \mu L / \Delta P
$$

where $\mathrm{V}$ is the bulk air velocity, $\mu$ is the dynamic viscosity, $\mathrm{L}$ is the length of the gravel column, and $\Delta P$ is the pressure difference. The resulting permeability is approximately $1.7 \times 10^{-8} \mathrm{~m}^{2}$.

Darcy's Law is generally considered valid for flow of a non-adsorbing gas through a permeable media if the associated Reynolds Number ( $R e$ ) is below some limit. However, the reported maximum value of Re for Darcy flow ranges from 0.1 to 75 (Scheidegger 1960). $\quad \operatorname{Re}$ is defined as follows

$$
\operatorname{Re}=\mathrm{V} \mathrm{D}_{\mathrm{P}} \rho / \mu \phi
$$

where $D_{P}$ is the particle size, $\rho$ is the fluid density, and $\phi$ is the porosity of the permeable media. The value of $D_{P}$ is not clearly defined for a media with a range of particle sizes. We can calculate approximate values for $\mathrm{Re}$ using a typical diameter for the gravel particles of $0.008 \mathrm{~m}$, determined from inspection and measurement, and a typical porosity of 0.4 . The values of Re for the four left-most data points on Figure 3 are approximately $10,18,25$, and 31 , respectively. Based on these calculations and a visual inspection of the velocity-pressure drop relationship shown on Figure 3, flow in this gravel does not deviate substantially from that described by Darcy's Law until Re exceeds 25 or 30 . However, significantly different Re values could be calculated because no specific criteria exist for distinguishing between Darcy and non-Darcy flow and no criteria exist for selecting the particle diameter used in the calculation of Re.

\section{MEASUREMENTS AND INSTRUMENTATION}

\section{Requirements}

To meet project objectives, a large number of parameters relevant to radon entry must be measured periodically. The required frequency of measurements varies greatly. Pressures differences between the interior of the structure and either the soil or the outdoor air can change rapidly and must be measured on a relatively short time scale such as fractions of a minute to hourly. Significant variations in atmospheric pressure, indoor and soil-gas radon concentrations, soil permeabilities and moisture contents, and the temperatures of indoor and outdoor air and soil will 
occur on a longer time scale that may range from tens of minutes to more than a week. Some parameters, such as soil permeability, soil-gas radon concentration, soil temperature, soil moisture content, and indoor-to-soil pressure difference vary substantially with location in the soil, thus, multi-point measurements are required throughout a large region of soil. In addition to these requirements for measursments, the instrumentation and control system must be capable of controlling the structure ventilation rate and the pressure difference that drives soil gas and radon entry (i.e., the difference between the indoor pressure and the pressure in the soil) via control of the rates of air flow into and out of the structure. For some experiments, we require very stable ventilation rates and pressure differences; however, to study transient radon entry we require dynamic control of the pressure differences that drive soil gas and radon entry. Table 1 lists the major parameters measured, the measurement ranges, maximum desired uncertainties, and the types of instrumentation used. The probes and instrumentation are described in the following paragraphs.

Permeability, Pressure, and Radon Concentration Measurements (well-screen probe)

A multi-purpose probe and associated measurement techniques were developed to monitor the pressure, permeability, and radon concentration at 32 locations in the soil surrounding the structure as depicted in Figure 1. To measure pressure in the soil, the probe is connected to a pressure transducer by opening a solenoid valve during a period with no flow through the probe. To measure the soil-gas radon concentration, a soil gas sample is drawn through the probe at approximately 200 $\mathrm{cm}^{3} / \mathrm{min}$ into a continuous radon monitor (probes are selected by opening solenoid valves). Soil permeability is measured by drawing soil gas through the probe and simultaneously measuring the soil gas flow rate and pressure in the probe.

Using one probe to measure three parameters reduces in the number of probes that need be fabricated and installed but results in three sets of design constraints for a single probe. To prevent the weight of air columns within tubing from interfering with accurate pressure measurements, the tubing connecting the probe to the pressure transducer must not have any vertical sections, or the temperature of air in vertical sections must be precisely known. For accurate permeability measurements, in addition to the same pressure measurement constraint, a well-defined soil-probe interface is required that does not change with time and any physical disturbance of the soil surrounding the probe should be minimized. In addition, a clear majority of the measured pressure drop must occur in the soil (not in the probe). Finally, to measure the soil-gas radon concentration without changing the concentration, the internal volume of the probe must be reasonably small to limit the volume of soil gas required to purge the probe during sampling.

To meet these objectives, a new type of probe was designed and fabricated. This probe uses a cylindrical stainless steel well screen $(15 \mathrm{~cm}$ long, $2.13 \mathrm{~cm}$ outer diameter) welded on one end to nominal $1 / 2$ inch pipe $(2.13 \mathrm{~cm}$ outer diameter) and welded on the other end to steel driving points. The diameter of the probe was based on the minimum size of commercially-available well screens. The well screen is fabricated from wire that is wound like the wire of a spring in a spiral pattern. Air can flow through the spiral gap which is smallest at the outside diameter of the well screen due to the use of wire with a triangular cross section (this configuration is designed to inhibit plugging of the well screen with sediment during normal use in water wells).

Prior to developing the well-screen probe, soil permeability was generally measured with a pipe-end probe (Turk et al. 1990). A small, high-permeability cavity is created in the soil at the end of the pipe-end probe. Relative to the pipe-end probe, the well-screen probe has two major advantages for permeability measurement. First, the soil-probe interface of the well-screen probe (i.e., direct contact between the soil and the well-screen) better defined and temporally more stable than the cavity at the end of a pipe-end probe. Second, the well-screen probe measures the permeability of a much larger region of soil, consequently the permeability measurement is less 
affected by the highly localized perturbations in soil permeability at the soil-probe interface. The volume of soil associated with the permeability measurement by each probe is estimated as follows. We represent the pipe-end probe approximately by a spherical cavity with diameter $D$, equal to the diameter of the pipe, surrounded by an infinite-diameter sphere of homogeneous soil. For this geometry, a closed form solution for the flow versus pressure drop relationship (Carslaw and Jager 1959) indicates that $90 \%$ of the pressure drop will occur in a sphere of soil with diameter $10 \mathrm{D}$ and volume of $524 \mathrm{D}^{3}$. In contrast, with a well-screen probe of the same diameter and a well-screen length of 7.05D (the configuration of our probe), $90 \%$ of the pressure drop occurs in an approximately-spherical soil region with a diameter of 28D and volume $11700 \mathrm{D}^{3}$, which is a 22 times larger volume. (This volume was based on a pressure field prediction of the numerical model described by Narasimhan et al. 1990. )

Most probes are installed horizontally, pass out of the structure through the walls, and therefore do not require any vertical sections of tubing between the probe and pressure transducer which is mounted within the structure at the same elevation. Vertical probes were obviously required for measurements below the slab floor. The seven probe depths are: (1) $0.25 \mathrm{~m}$ below the soil surface, (2) $0.8 \mathrm{~m}$ depth which is mid-depth of the wall, (3) slab depth of approximately $1.6 \mathrm{~m}$, and (4) $0.24,0.50,1.7$, and $2.4 \mathrm{~m}$ below the slab floor. The horizontal probes were installed with well screens located three distances from the structure, one in the backfill zone near the structure, the others approximately 1.7 and 2.4 meters from the wall. There is one additional horizontal "reference probe" used to reference the structure pressure to a region in the soil which is almost uninfluenced by the structure (approximately 5 meters from the structure at the level of the slab floor).

To calculate soil permeability from the measured pressures and flow rates in the well-screen probes, the probe shape factor must be known. The shape factor $S$ is a proportionality constant in the relationship between flow rate $Q$ and pressure drop $\Delta P$, as indicated by the following equation

$$
\mathrm{Q}=\mathrm{S} k \Delta \mathrm{P} / \mu \text {. }
$$

The shape factor depends on the probe geometry, i.e., the length and diameter of the well screen. In addition, $S$ depends (to some extent) on the location of the probe relative to the structure and soil surface and on the probe orientation (vertical or horizontal). We used a numerical model (Narasimhan et al. 1990, Tsang and Narasimhan 1991) to compute values for $\mathbf{S}$ assuming homogeneous and isotropic soil. The shape factor was computed for the installation conditions at the first site and, for these conditions, the shape factor varied from 0.29 to $0.35 \mathrm{~m}$. This range is very small relative to the range in soil permeabilities, consequently, we use a value of 0.3 $m$ for all permeability calculations.

\section{Soil Moisture Measurement}

Soil moisture content affects the permeability of the soil and soil-gas radon concentrations. In addition, movement of water within the soil may cause pressures that influence soil-gas entry rates. We employ a technique known as Time Domain Reflectrometry (TDR) to obtain the moisture content from the electromagnetic pulse reflected by a waveguide implanted in the soil. The measurement technique, described by Topp and Davis (1985), is based on the change in dielectric constant of soil associated with a change in soil moisture content. The waveguide consist of three parallel $20 \mathrm{~cm}$-long stainless steel rods spaced approximately $2.5 \mathrm{~cm}$ apart. Presently, we automatically measure soil moisture at a single location twice per day. On several occasions, the probe has been manually placed at a variety of locations for measurements. We are presently deploying new hardware and software by the TDR vender which permit automated measurements at multiple locations and depths below the soil surface.

Temperature Measurements

Soil temperatures are monitored to allow examination of the importance of 
buoyancy-driven soil-gas flows on radon entry and to determine the contribution of soil gas temperature variations to the indoor-to-soil pressure differences. We expect soil temperatures to vary slowly over time, to vary with depth, and to vary with distance from the structure if the structure temperature is distinct from the temperature of the undisturbed soil. Thermocouples were inserted in two vertical plastic pipes installed in the soil, one in the backfill region approximately $0.4 \mathrm{~m}$ from the structure, the other in the undisturbed soil approximately $5 \mathrm{~m}$ from the structure. Each pipe has thermocouples located approximately $20,100,180$, and $240 \mathrm{~cm}$ below the soil surface. Vertical heat conduction within the pipes was minimized by filling the pipe with dry sand and sealing the top after thermocouple installation. We also use thermocouples to measure the temperature of the air within the structure at two locations and the temperature of the inner concrete surfaces of the structure at four locations.

\section{Radon Concentration Measurements}

Accurate radon concentration measurements are critical for this project. We use one continuous radon monitor (CRM) as described by Nazaroff et al. (1983) to measure the radon concentration in the indoor air which is vigorously mixed with a fan, a second CRM to measure the concentration of radon in the soil gas that enters through the slots, and a third CRM to measure radon concentrations in soil-gas samples drawn from the well-screen probes.

The measurements of soil-gas radon were a design challenge due to the need to monitor samples from numerous locations with a single (or small number of) CRMs. In the conventional measurement protocol with a CRM, counts from the radon and radon-progeny decays within the scintillation cell of the CRM are accumulated for a thirty minute period with continuous flow of a sample stream through the cell. The 30 minute period is too great for experiments that require frequent radon measurements at a substantial fraction of the 32 measurement locations. In addition, a short sampling and counting period is desired to minimize the amount of soil gas withdrawn from the soil because excessive sample volumes could affect radon concentrations within the soil and cause above-grade air to be drawn into samples from near the soil surface.

The time required for soil gas radon measurements is reduced by purging one probe and the associated tubing of the prior (old) soil gas sample while simultaneously counting alpha decays in the sample drawn from the previouslypurged probe. Minimization of the duration of the sampling and counting period, necessitated adoption of a measurement and data analysis procedure that accounts for the radioactive decay of radon progeny deposited on scintillation cell walls during previous measurement periods (Busigin et al. 1979). A dynamic calibration of the CRM was required (i.e., a recording of performance during periods of known rapid changes in radon concentration). To determine measurement uncertainty as a function of the duration of the period of sampling and counting, statistical analyses were performed as described by Modera and Bonnefous (1991). In the final protocol selected for most experiments, the duration of the sampling and counting period is eight minutes and the integrated number of counts is read and stored every minute during the eight-minute period. Typically, radon concentration is monitored three times per day at twelve of the 32 probe locations.

To draw a representative sample of soil gas entering through the slots into a CRM, the sample is drawn from 12 equal-length small-diameter sample tubes inserted in the slots. The sample flow rate from the slots is only $20 \mathrm{cc} / \mathrm{min}$, a small fraction of the soil gas entry rate. Laboratory experiments confirmed that the CRM performs properly with this low sample flow rate (the normal sample flow rate is 200 $\mathrm{cc} / \mathrm{min})$.

Measurement and Control of Ventilation and Sample Strcam Flow Rates

Mass flow controllers regulate and monitor the flow rates of air supplied to and exhausted from the structure. The structure is depressurized by maintaining a 
larger exhaust than supply flow. Control of the depressurization is typically via modulation of the exhaust flow rate. Generally, we control the pressure difference at slab level between the interior of the structure and the end of the five-meter-long horizontal well-screen probe (i.e., the reference probe) which extends substantially outside of the region of influence of the structure. The data acquisition and control system (described subsequently) uses a proportional-integral-differential control loop to control the depressurization. Structure depressurizations up to $100 \mathrm{~Pa}$ are possible, resulting in measurable depressurizations at all probes. The control system also permits the depressurization to be varied over time for studies of transient radon entry.

Another mass flow controller regulates and monitors the rates of flow from the well screen probes. The flow rate data are used to compute soil permeabilities.

\section{Meteorologic Parameters}

Standard methods described in Table 1 are used to monitor outdoor temperature, wind speed, and precipitation. However, the barometric pressure transducer is unusually sensitive. This transducer has a $0.2 \mathrm{~Pa}$ sensitivity out of $10^{5}$ $\mathrm{Pa}$ total atmospheric pressure. A high sensitivity is raquired to assess the impact of small changes in barometric pressure on radon entry rates.

\section{Data Acquisition and Control}

Automated measurements and control of experiments are accomplished with a data acquisition/control system based on an IBM-AT compatible computer with plug-in input and output cards and commercial multi-tasking data acquisition software. The data acquisition software allows for several independent tasks to be programmed, including: control of pressures in the structure; continuous routine data acquisition; and periodic permeability, soil-gas radon and soil moisture measurements. Continuous da. acquisition, which includes pressure, temperature and weather measurements, can occur at any frequency lower than $10 \mathrm{~Hz}$.

\section{Instrumentation System Problems}

One atypical instrumentation-system problem is the occasional flow of ground water into manifolds and valves connected to the well-screen probes. We believe that we have solved this problem by installing collection vessels (plastic bottles) at the structure-ends of affected probes. Water drains into the vessels through tee connections; however, the sample streams do not flow through the vessels. Another unusual problem is condensation of water from the moist soil gas samples when the sample tubing passes through a region with a temperature below soil temperature (i.e., during the winter). A system has been added to condense water from the sample streams directed to the CRMs. In addition, we have added heat tape to increase the temperature of conduit that encloses the sample tubing where this conduit is exposed to outdoors. These measures have reduced condensation problems; however, further experience is required to determine if the problems have been eliminated.

\section{EXPERIMENTS}

\section{Experimental Approaches}

Our experiments are designed primarily to examine the relationships between the controllino parameters, such as soil prcperties and structure depressurization, and the resulting pressures and radon concentrations in the soil plus the soil gas and radon entry, ates. The impact of site-to-site differences in soil conditions on radon entry and on the other measured variables will, in the future, be determined by comparing the data obtained from identical structures and operating conditions at the different sites. Similarly, the effects of subslab aggregate will be determined via a comparison of the data from the two different structures located at the same site in a region with relatively homogeneous soil. 
At each site, our plans include cycling between a number of different methods of controlling the indoor-outdoor pressure difference while other parameters are constant, vary naturally (e.g., soil moisture), or are intentionally modified (e.g. slot width). To date, the duration of the operational cycles has been approximately one to three weeks.

In one mode of pressure control, the structure depressurization at slab level is maintained constant with respect to the pressure in the soil at the end of the fivemeter-long reference probe. This has been the primary mode of operation to date. In this mode, the impact of atmospheric pressure fluctuations on soil gas entry is reduced compared to the case with a constant indoor-outdoor pressure difference at the soil surface. The pressure difference is usually maintained between 20 and 100 $\mathrm{Pa}$, which is large compared to the typical depressurization of houses, in order to increase the magnitude (and thus increase measurement accuracy) of the resultant changes in soil gas pressures and radon concentrations. By varying the pressure difference, we are checking for the expected linear increase in soil gas entry rate with pressure difference and quantifying the decrease in entering soil gas radon concentrations when soil gas velocities are high.

In another control mode, not yet utilized, the indoor-outdoor pressure difference will again be maintained constant but the reference outdoor pressure will be at the soil surface. The driving force for soil gas and radon entry will, in this case, be influenced by the time lags between variations in atmospheric pressure and soil gas pressures. We may find evidence of temporal variations in radon entry rates and periodic pumping of soil gas into and out of the basements through the penetrations to the soil.

We have completed two types of transient experiments. In one case, the indoor-outdoor pressure difference is changed abruptly and data are collected rapidly as the measured parameters such as soil-gas pressures, soil-gas radon concentrations, and radon entry rates, respond to this step change. In another control mode, the indoor-outdoor pressure difference is varied in a sinusoidal manner, to simulate barometric pressure variations, check for time lags and phase shifts in the pressures within the soil, and monitor the effects on soil gas radon concentrations. To date, the period of the oscillation has been either very short (fractions of a minute) or twelve hours.

In yet another mode of operation (not yet used), designed primarily to investigate the importance of buoyancy-driven flow of soil gas, we will raise the temperature within the structure substantially (e.g. $20^{\circ} \mathrm{C}$ ) above soil temperatures for a sufficient period to raise soil-gas temperatures near the substructure. With the elevated indoor temperature, the indoor-outdoor pressure difference will be maintained constant using the mechanical ventilation/pressure control system or, at other times, allowed to float naturally. When the indoor-outdoor pressure difference floats, we expect to obtain information that helps to explain diurnal variations in indoor radon concentrations. Data from periods with a constant indoor-outdoor temperature difference will be compared to similar data from periods without an elevated indoor temperature to indicate the effects of buoyancy-driven flow on radon entry.

A variety of additional experiments have been undertaken. These include experiments to evaluate radon entry by diffusion and to characterize the structure. We also plan experiments to evaluate proposed diagnostic techniques for studying radon entry in actual houses, and experiments to validate models of radon mitigation system performance.

\section{Examples of Experimental Results}

Figure 4 shows the pressure field and soil permeability field in the soil around the structure. The pressure data were collected during an experiment with the interior structure pressure at slab level maintained approximately $22 \mathrm{~Pa}$ below the pressure at the slab-level reference probe. The pressure field is indicated by values of 
percent pressure coupling which equal the depressurization in the soil expressed as a percentage of the $22 \mathrm{Fa}$ depressurization of the structure. In most respects, the pressure coupling pattern corresponds qualitatively with expectations and numerical predictions (Revzan et al. 1990) for a depressurized basement with a layer of subslab aggregate. Because of the high-permeability aggregate layer, there is not a steep pressure gradient near the siots. Instead, the pressure coupling just beneath the aggregate layer is nearly $100 \%$ which indicates that the pressure drop in the slots (width $=3.17 \mathrm{~mm}$ ) and in the aggregate is negligible. In general, the pressure coupling decreases gradually with distance from the aggregate. The pressure coupling should decrease with horizontal distance from the walls of the structure if the soil and backfill have the same homogeneous isotropic permeability. Inconsistent with this expectation, near the soil surface the measured pressure coupling actually increases slightly with distance from the structure, especially on the south side of the structure. Because the same pressure transducer is used to measure all pressures at the same elevation, this deviation from our expectations is unlikely to be caused by measurement error. (The error estimates on the figure are useful for assessing the significance of differences in pressure coupling measured with different pressure transducers at different elevations). However, the non-uniform soil permeability, in particular the generally higher permeability of the undisturbed soil relative the permeability of the backfill, is a possible explanation for the increased pressure coupling further from the structure walls. Garbesi et al. (1992) discuss the pressure field data in more detail and show that the measured pressure field and the associated soil gas entry rates deviate substantially from quantitative predictions made with a numerical model.

The permeabilities shown on Figure 4 vary over more than two orders of magnitude from $2 \times 10^{-13} \mathrm{~m}^{2}$ to $270 \times 10^{-13} \mathrm{~m}^{2}$. The backfill permeability is relatively uniform and tends to be lower than the soil permeability at the same elevation. At several locations within the deep soil, the permeability is low enough (e.g., $2 \times 10^{-13}$ $\mathrm{m}^{2}$ ) to preclude significant convective flow of soil gas and radon at that location. The spatial pattern of measured soil permeabilites is consistent with our understanding of the structure of the soil based on analyses of soil core samples and observations of the soil walls of the excavations (Wollenberg et al. 1990). The upper one-to-two meters of soil is extensively weathered. All the measured permeabilities in this region exceed $10^{-12} \mathrm{~m}^{2}$, except for one measured value at approximately two meters depth. Below approximately two meters depth, differential weathering of the parent quartz diorite has resulted in zones that range from a highly decomposed soillike media to relatively intact highly-weathered rock (soft enough for manual excavation with a shovel). Some of the measured permeabilities in this deeper soil are very low, e.g., $2 \times 10^{-13} \mathrm{~m}^{2}$. We would expect these low permeabilities in the zones that are less extensively weathered.

At two locations, the percent pressure coupling is appreciable (38\%) but the measured permeability is only $2 \times 10^{-13} \mathrm{~m}^{2}$. These data could be from regions of low permeability soil surrounded by much higher permeability soil. The pressure in such low permeability regions will approximately equal the average of the surrounding pressures. However, these data are inconsistent with the existence of an unbroken low-permeability layer of soil located between the slab floor and the measurement location.

Figure 5 shows the steady state $R n$ concentrations in the soil and also in the soil gas that enters through the slots. These data were collected during the previously referenced experiment with a $22 \mathrm{~Pa}$ depressurization. As expected, concentrations increase with depth below the soil surface. This general trend may be explained by Rn diffusion from the surface soil to the atmosphere and air flow into and out of the surface soil driven by atmospheric pressure changes. However, the large difference between the radon concentrations of 20 to $30 \mathrm{kBq} \mathrm{m}$ m $^{-3}$ at approximately one and two meters depth and concentrations of $100 \mathrm{kBq} \mathrm{m}^{-3}$ at four-to-five meters depth is surprising. Based on modeling by Revzan et al. (1991) for soil with a uniform $\mathrm{Ra}$ concentration and emanation fraction and a permeability less than $10^{-10}$ 
$\mathrm{m}^{2}$, we did not expect substantial increases in soil gas $\mathrm{Rn}$ concentration below the level of the slab floor. Measured $R a$ concentrations and emanation fractions in the soil between 1.5 and $6 \mathrm{~m}$ depth vary by only 25\% (Fisk et al. 1989) and therefore, do not explain these findings. Possibly, the soil gas flow may be substantially decreasing radon concentrations in the soil at elevations above the slab floor because the measured flow is much greater than predicted for a soil with a homogeneous and isotropic permeability equal to the average measured permeability (Garbesi et al. 1992). This potential explanation is being investigated.

\section{SUMMARY}

In summary, we have designed and fabricated structures and an instrumentation system specifically for research on soil gas and radon entry into basements. This facility is unique in several respects: (1) the pressure differences that drive soil gas entry are experimentally controlled; (2) leakage paths to the soil are controlled; and (3) the instrumentation is extensive and yields the pressure fields and radon concentration fields in the soil as well as soil gas entry rates. Consequently, the facility is ideally suited for evaluation and verification of radon entry models and for investigations of the dependence of radon and soil gas entry rates on characteristics of the soil and structure, and on indoor-to-soil pressure differences and atmospheric pressure fluctuations. Experiments have been underway for approximately one year to investigate the rate of advective and diffusive entry. The associated pressure and radon concentration fields in the soil have been mapped as a function of the depressurization of the structure and the seasonally-varying soil properties. Investigating substantial discrepancies between the measured data and predictions of numerical models is a major present focus of this research project.

\section{REFERENCES}

Bowman, R.H. and Estrada, D.C. (1980) "Soil survey of Santa Cruz County, Calitornia". U.S. Department of Agriculture, Soil Conservation Service.

Busigin, A., Van Der Vooren, A.W., and Phillips, C.R. (1979) "Interpretation of the response of continuous radon monitors to transient radon concentrations". Health Physics 37, pp. $659-667$.

Carslaw H.S. and Jaeger (1959) Conduction of Heat In Solids, 2nd Edition. Oxford University Press, Oxford. ISBN 0198533039.

Dimbylow, P.J. (1987) "The solution of the pressure driven flow equation for radon ingress through cracks in concrete foundations". Radiation Protection Dosimetry 18(3), pp. 163-167.

DSMA Acton Ltd. (1985) "A computer study of soil gas movement into buildings". Report 1389/1333, Department of Health and Welfare, Ottawa.

Dudney, C.S. et al. (1989) "Investigation of radon entry and effectiveness of mitigation measures in seven houses in New Jersey". Oak Ridge National Laboratory, ORNL-6487, Oak Ridge, TN.

Eaton, R.S. and Scott, A.G. (1984) "Understanding radon transport into houses". Radiation Protection Dosimetry 7, pp. 251-253.

Fisk, W.J., Flexser, S., Gadgil, A.J., Holman, H.Y., Modera, M.P., Narasimhan, T.N., Nuzum, T., Revzan, K.L., Sextro, R.G., Smith, A.R., Tsang, Y.W., and Wollenberg, H.A. (1989) "Monitoring and modeling of radon entry into basements: a status report for 
the small structures project". Lawrence Berkeley Laboratory Report, LBL-27692, Berkeley, CA.

Flexser, S. and Wollenberg, H.A. (1992) "Distribution of radon sources and its effect on radon emanation in granitic soil at Ben Lomond Mountain, California". In preparation. Lawrence Berkeley Laboratory Report, Berkeley, CA.

Garbesi, K.M., Sextro, R.G., Fisk, W.J., Modera, M.P., and Revzan, K.L. (1992) "Soil Gas Entry Into an Experimental Basement: Model-Measurement Comparisons and Seasonal Effects". Lawrence Berkeley Laboratory Report, LBL-31873, Berkeley, CA. Submitted to Environmental Science and Technology.

Leo, G. (1967) "The plutonic and metamorphic rocks of the Ben Lomond Mountain area, Santa Cruz County, California. California Division of Mines and Geology Special Report 91, pp. $27-43$.

Loureiro, C.O. (1987) "Simulation of the steady state transport of radon from soil into houses with basements under constant negative pressure". Lawrence Berkeley Laboratory Report, LBL-24378, Berkeley, CA.

Modera, M.P. and Bonnefous, Y. (1991) "Radon concentration measurement in multiplexed samples with a continuous radon monitor". Lawrence Berkeley Laboratory Report, LBL-30742, Berkeley, CA.

Mowris, R.J. and Fisk, W.J. (1988) "Modeling the effects of exhaust ventilation on ${ }^{222} \mathrm{R} n$ entry rates and indoor ${ }^{222} \mathrm{R} n$ concentrations". Health Physics 54, pp. 491 - 501.

Narasimhan, T.N., Tsang, Y.W., and Holman, H.Y. (1990) "On the potential importance of transient air flow in advective radon entry into buildings". Geophysical Research Letters 17 (6), pp. $821-824$.

Nazaroff, W.W. and Nero, A.V. editors (1988) Radon and its decay products in indoor air. John Wiley \& Sons, New York.

Nazaroff, W.W., Offermann, F.J., and Robb, A.W. (1983) "Automated system for measuring air-exchange rate and radon concentration in houses". Health Physics 45(2), pp. 525-537.

Revzan, K.L. and Fisk W.J. (1990) "Modeling radon entry into houses with basements: the influence of structural factors". Lawrence Berkeley Laboratory Report, LBL28109, Berkeley, CA. To be published in Indoor Air.

Revzan, K.L., Fisk, W.J., and Gadgil, A.J. (1991) "Modeling radon entry into houses with basements: model description and verification". Indoor Air 1(2), pp. 173 - 189.

Revzan, K.L., Fisk, W.J., and Sextro, R.G. (199/b) "Modeling radon entry into Florida houses with concrete slabs and concrete block stemwalls". Lawrence Berkeley Laboratory Report, LBL-30005, Berkeley, CA.

Scott, A.G. (1983) "Computer modeling of radon movemen:". In: EML Indoor Radon Workshop. (editors: A. C. George, W. Lowder, I Fisenne, E.O. Knutson, and L. Hinchcliffe) Report EML-416, Environmental Measurements Laboratory, New York.

Scheidegger, A.E. (1960) The physics of flow through porous media. 2nd Ed., Macmillan, New York. 
Sherman, M. H. (1985) "Air infiltration in buildings". In: Energy sources: Conservation and Renewables. American Institute of Physics, New York.

Topp, G.C. and Davis, J.L. (1985) "Measurement of soil-water content using timedomain reflectrometry (TDR): a field evaluation". Soil Sci. Am. J. 49, pp. 19-24.

Tsang, Y.W. and Narasimhan, T.N. (1991) "Effect of periodic atmospheric pressure variation on radon entry into buildings". Lawrence Berkeley Laboratory Report, LBL31164, Berkeley, CA. Submitted to J. Geophysical Research.

Turk, B.H., Prill, R.G., Grimsrud, D.T., Moed, B.A., and Sextro, R.G. (1990) " Characterizing the occurrence and variability of radon in Pacific Northwest homes". J. Air Waste Manage. Assoc. 40, pp. 498 - 506.

White, F.M. (1974) Viscous fluid Flow, McGraw Hill.

Wollenberg H.A., Flexser, S., Sextro, R.G., and Smith A.R. (1990) "Selection and characterization of a radon experimental site". Earth Sciences Division Annual Report, 1989. Lawrence Berkeley Laboratory Report, LBL-27900, pp. 140 - 145.

\section{ACKNOWLEDGMENTS}

The authors would like to acknowledge the contributions of many who have assisted with this effort. R. Ackhart, D. Nesbitt, and W. Harnden contributed greatly via their roles in the design of the structures and slot systems and oversight of fabrication efforts. Similirly, D. Lippert and R. Solbau contributed immeasurably to the structure construction process. C. Khalizadeh and D. Dickerhoff have provided valuable assistance in the development of the instrumentation and G. San Martin conducted tests of the adjustable-width slots. T. Tokohaga provided valuable advice on the characterization of soil and backfill properties and assisted with characterization of soil samples. T. Patock, in our purchasing department, was extremely effective in handling outside contracts. .

This work was supported by the Director, Office of Energy Research, Office of Health and Environmental Research, Environmental Sciences Division and by the Assistant Secretary for Conservation and Renewable Energy, Office of Building Technologies, Building Systems and Materials Division of the U.S. Department of Energy (DOE) under Contract DE-AC03-76SF00098. 
Table 1. Parameters Measured and Measurement Methods

\begin{tabular}{|c|c|c|c|}
\hline $\begin{array}{l}\text { Parameter(s) } \\
\text { [\# of locations] }\end{array}$ & Range & $\begin{array}{l}\text { Target Max } \\
\text { Uncertainty }\end{array}$ & $\begin{array}{l}\text { Measurement } \\
\text { Method/Instruments }\end{array}$ \\
\hline $\begin{array}{l}\text { Indoor-to-soil pressure } \\
\text { difference }[33]^{*}\end{array}$ & $0-100 \mathrm{~Pa}$ & $0.1 \mathrm{~Pa}$ or $2 \%$ & $\begin{array}{l}\text { Electronic pressure } \\
\text { transducers }\end{array}$ \\
\hline $\begin{array}{l}\text { Indoor-to-outdoor } \\
\text { pressure difference [1] }\end{array}$ & $0-100 \mathrm{~Pa}$ & $0.1 \mathrm{~Pa}$ or $2 \%$ & $\begin{array}{l}\text { Electronic pressure } \\
\text { transducer }\end{array}$ \\
\hline Barometric pressure [1] & $0.96-1.06 \times 10^{5} \mathrm{~Pa}$ & $1 \mathrm{~Pa}$ & $\begin{array}{l}\text { Electronic pressure } \\
\text { tran;ducer }\end{array}$ \\
\hline Soil permeability [33]* & $10^{-13}-10^{-9} \mathrm{~m}^{2}$ & $30 \%$ & $\begin{array}{l}\text { Measure pressure and flow } \\
\text { in probes }{ }^{+}\end{array}$ \\
\hline $\begin{array}{l}\text { Soil temperature [4] } \\
\text { and backfill temp. [4] }\end{array}$ & -20 to $40^{\circ} \mathrm{C}$ & $0.5^{\circ} \mathrm{C}$ & $\begin{array}{l}\text { Thermocouples at } 4 \text { depths } \\
\text { in probes inserted into soil } \\
\text { and backfill }\end{array}$ \\
\hline Soil moisture content $[1] \xi$ & $0-0.6 \mathrm{~m}^{3} / \mathrm{m}^{3}$ & $0.03 \mathrm{~m}^{3} / \mathrm{m}^{3}$ & $\begin{array}{l}\text { Time domain reflectometry } \\
\text { (see text) }\end{array}$ \\
\hline Soil gas $R n$ conc. $[33]^{*}$ & $>20 \mathrm{~Bq} / \mathrm{m}^{3}$ & $\begin{array}{l}10 \% \text { (above } \\
\left.200 \mathrm{~Bq} / \mathrm{m}^{3}\right)\end{array}$ & Continuous radon monitor \\
\hline Indoor $R n$ conc. [1] & $"$ & $"$ & " \\
\hline Rn conc. in slots [1] & 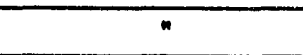 & $"$ & $"$ \\
\hline $\begin{array}{l}\text { Air flow rate into } \\
\text { and out of structure }\end{array}$ & $5-50 \mathrm{~L} / \mathrm{min}$ & $0.5 \mathrm{~L} / \mathrm{min}$ & $\begin{array}{l}\text { Mass flow } \\
\text { meters/controllers }\end{array}$ \\
\hline Outdoor temperature [1] & -20 to $40^{\circ} \mathrm{C}$ & $0.5^{\circ} \mathrm{C}$ & Aspirated thermocouple \\
\hline Wind speed & 0 to $\mathrm{m} / \mathrm{s}$ & $0.3 \mathrm{~m} / \mathrm{s}$ & Cup anemometer \\
\hline Precipitation & $0.5 \mathrm{~cm} / \mathrm{hr}$ & $0.1 \mathrm{~cm} / \mathrm{hr}$ & Tipping bucket rain gage \\
\hline
\end{tabular}

- 33 possible measurement locations in soil surrounding structure; location selected via manifolds and solenoid valves.

+ Using electronic pressure transducers and mass flow meter/controller.

$\xi$ One location at present; measurements at multiple locations and depths are planned. 

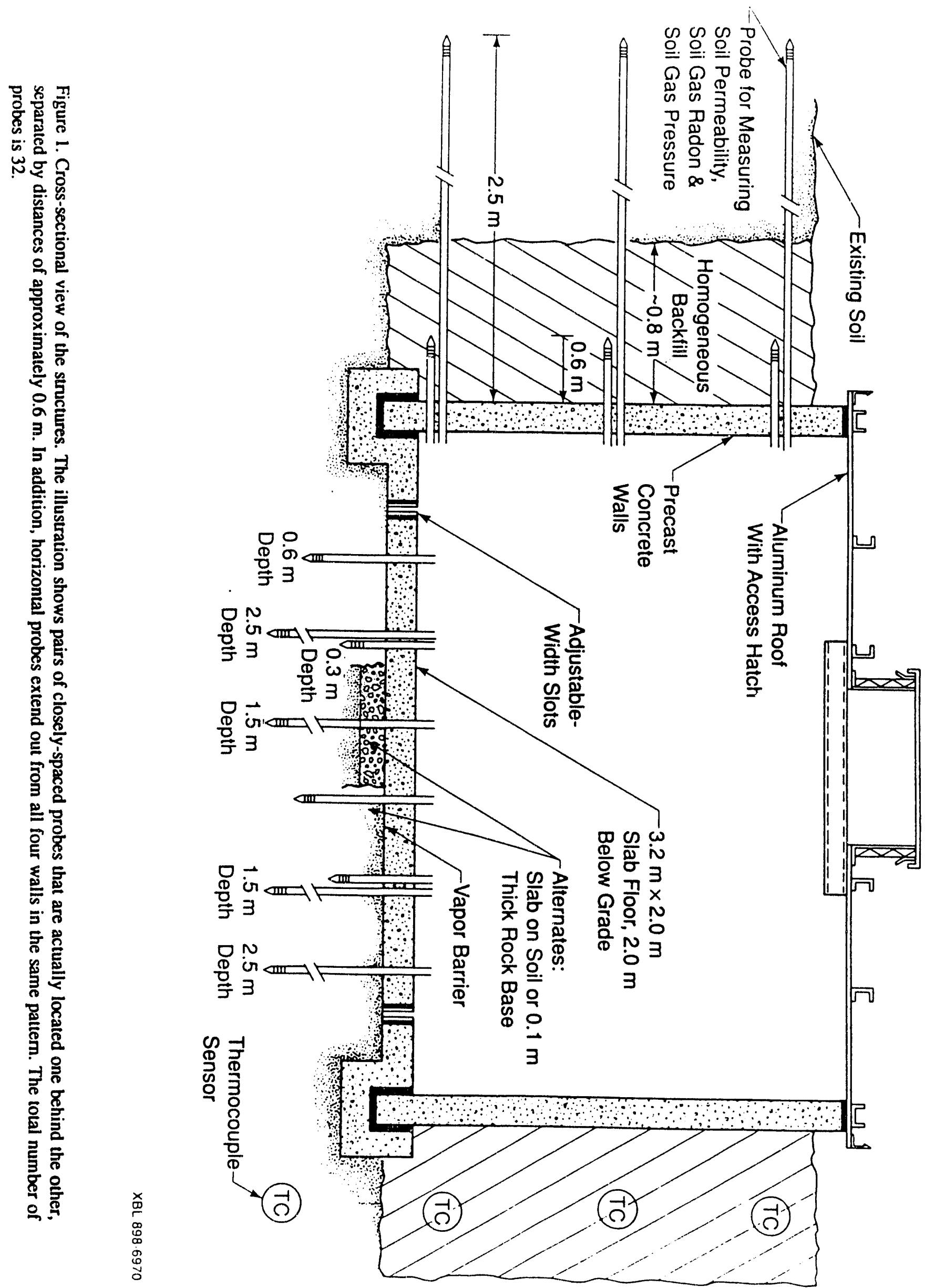


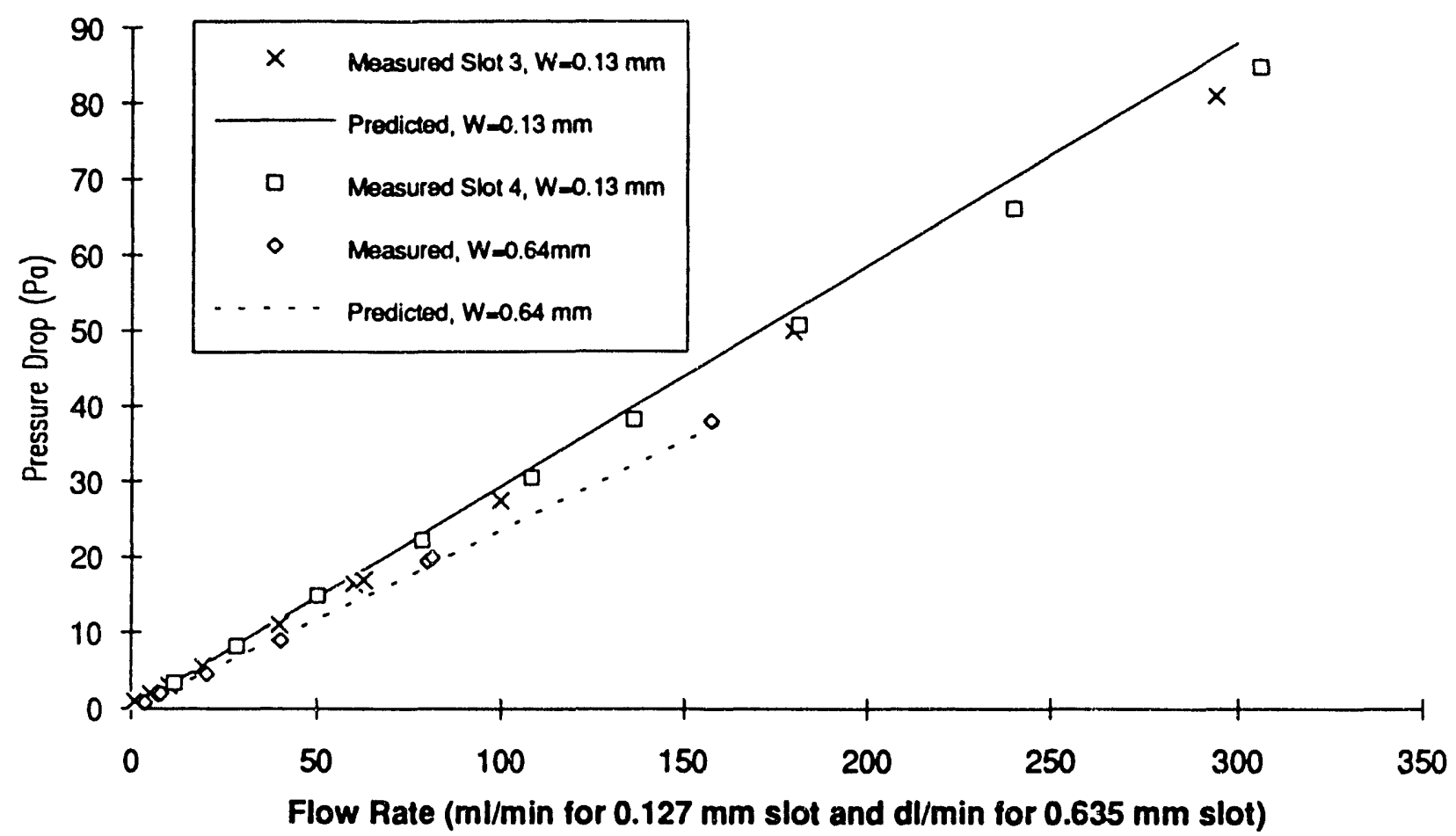

Figure 2. Measured and predicted pressure drop versus flow rate in slots of width 0.13 and $0.64 \mathrm{~mm}$. The prediction is via the equation $\Delta \mathrm{P}=\left((12 \mu \mathrm{Z} \mathrm{Q}) /\left(\mathrm{L} \mathrm{W}^{3}\right)+\right.$ I $(1.67 \rho / 2)(Q /(W ~ L))^{2}$ ] ) from White (1974) where: $\mu$ is the dynamic viscosity, $Z$ is the length of the slot in the direction of flow $(0.152 \mathrm{~m}), Q$ is the flow rate, $L$ is the length of the slot perpendicular to the flow $(0.927 \mathrm{~m}), W$ is the slot width, and $\rho$ is the density. 


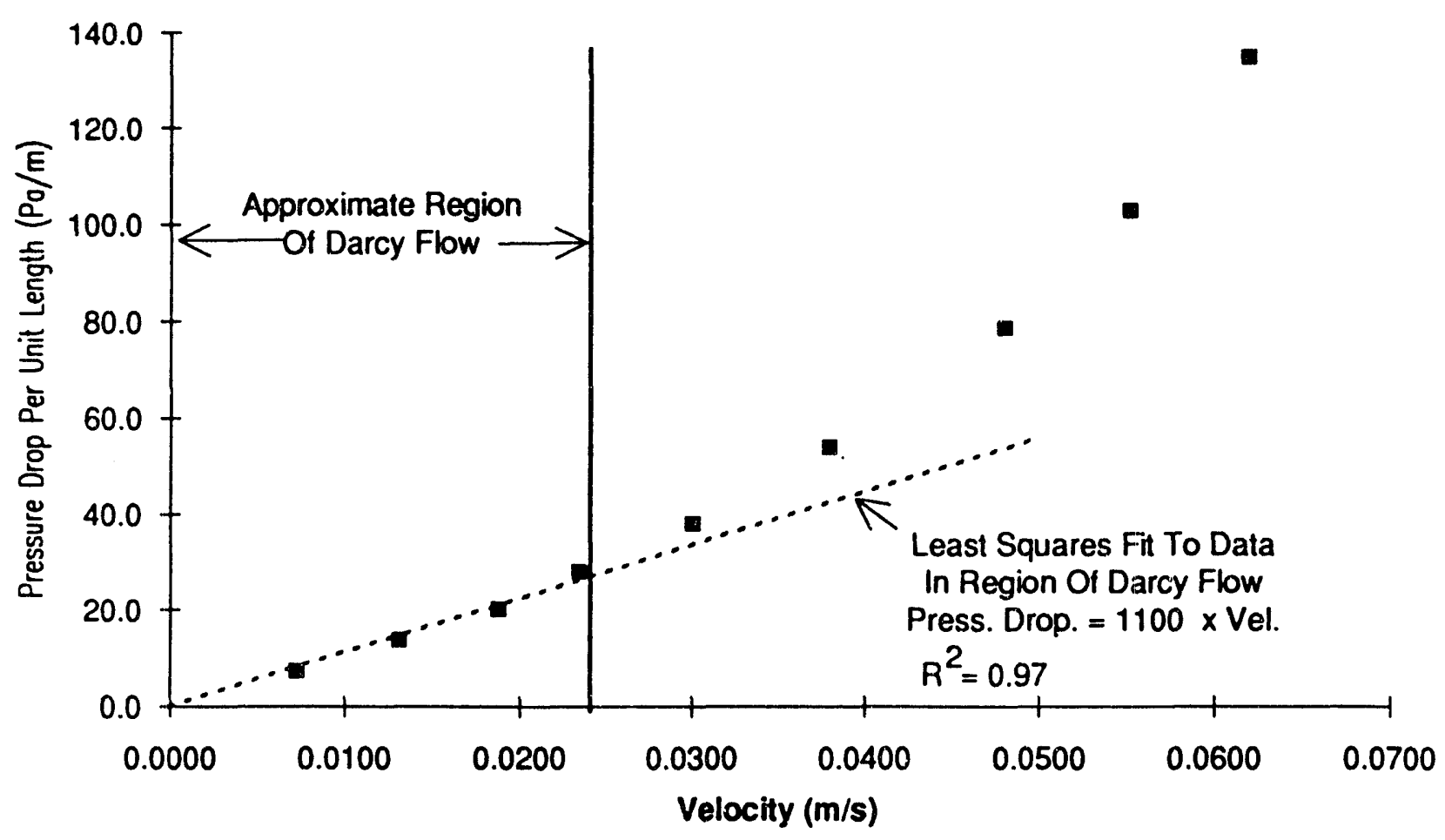

Figure 3. Measured pressure drop versus velocity in a sample of the gravel installed beneath the floor of one structure. The permeability computed from the linear range of data is $1.7 \times 10^{-8} \mathrm{~m}^{2}$. 

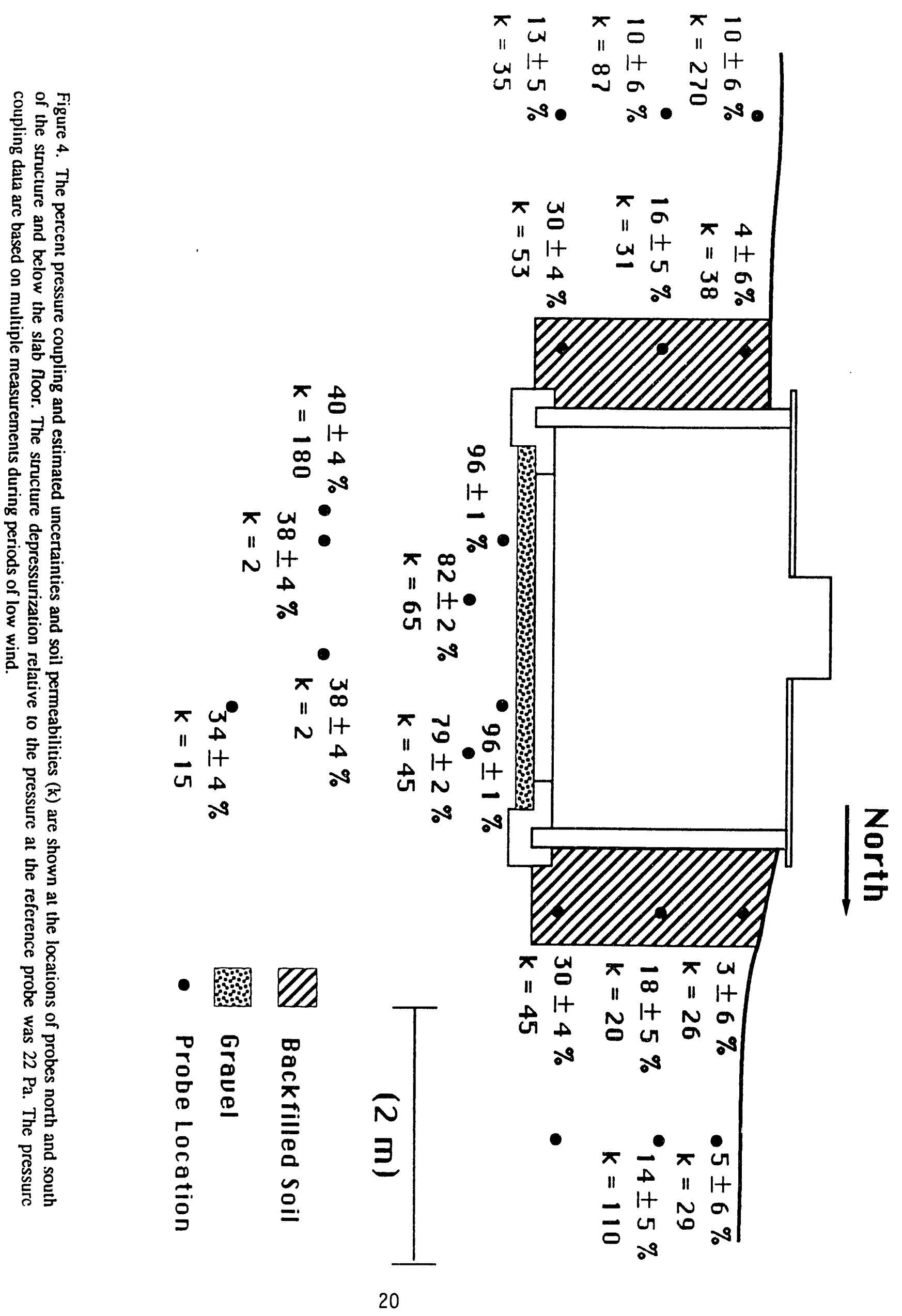


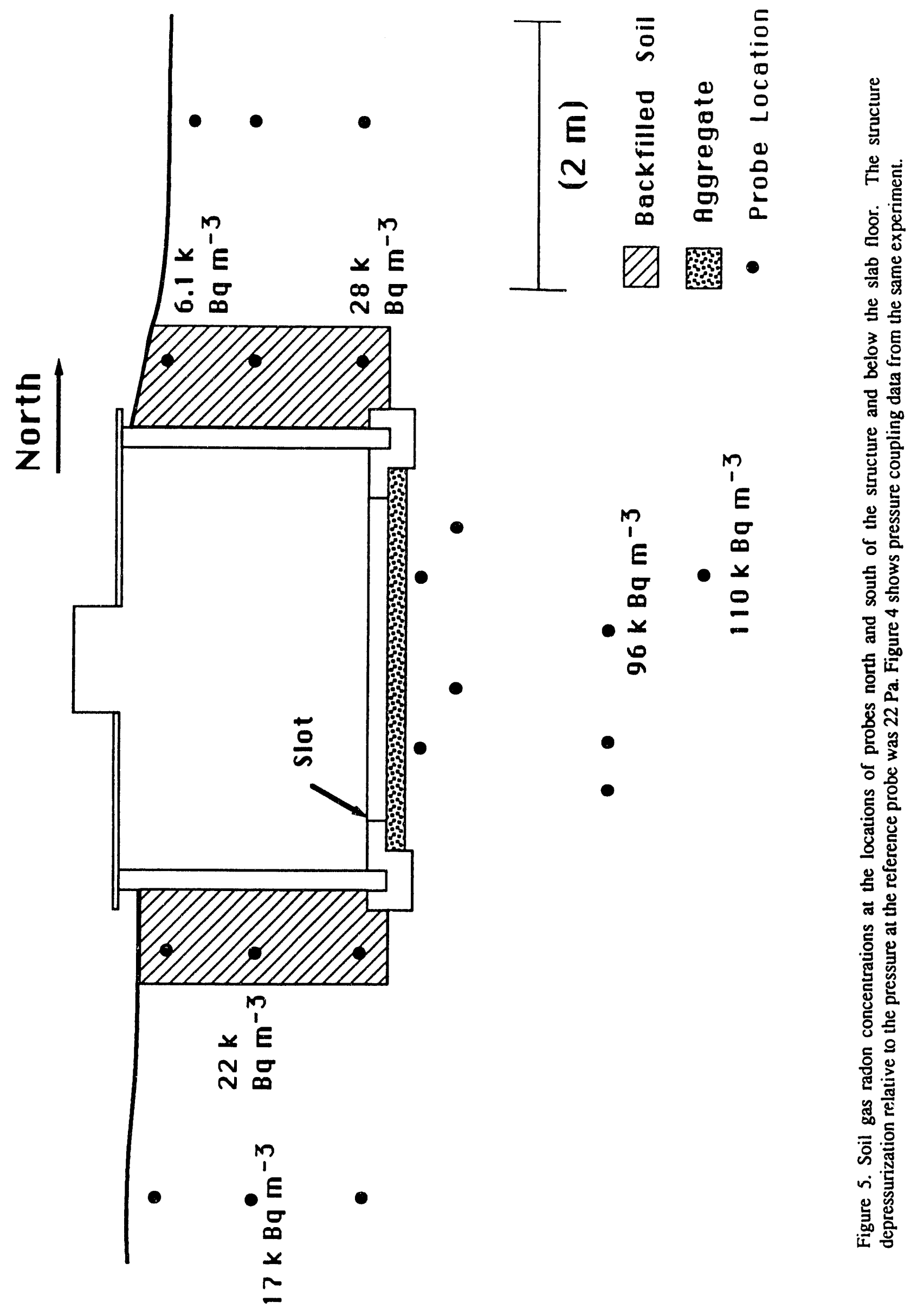



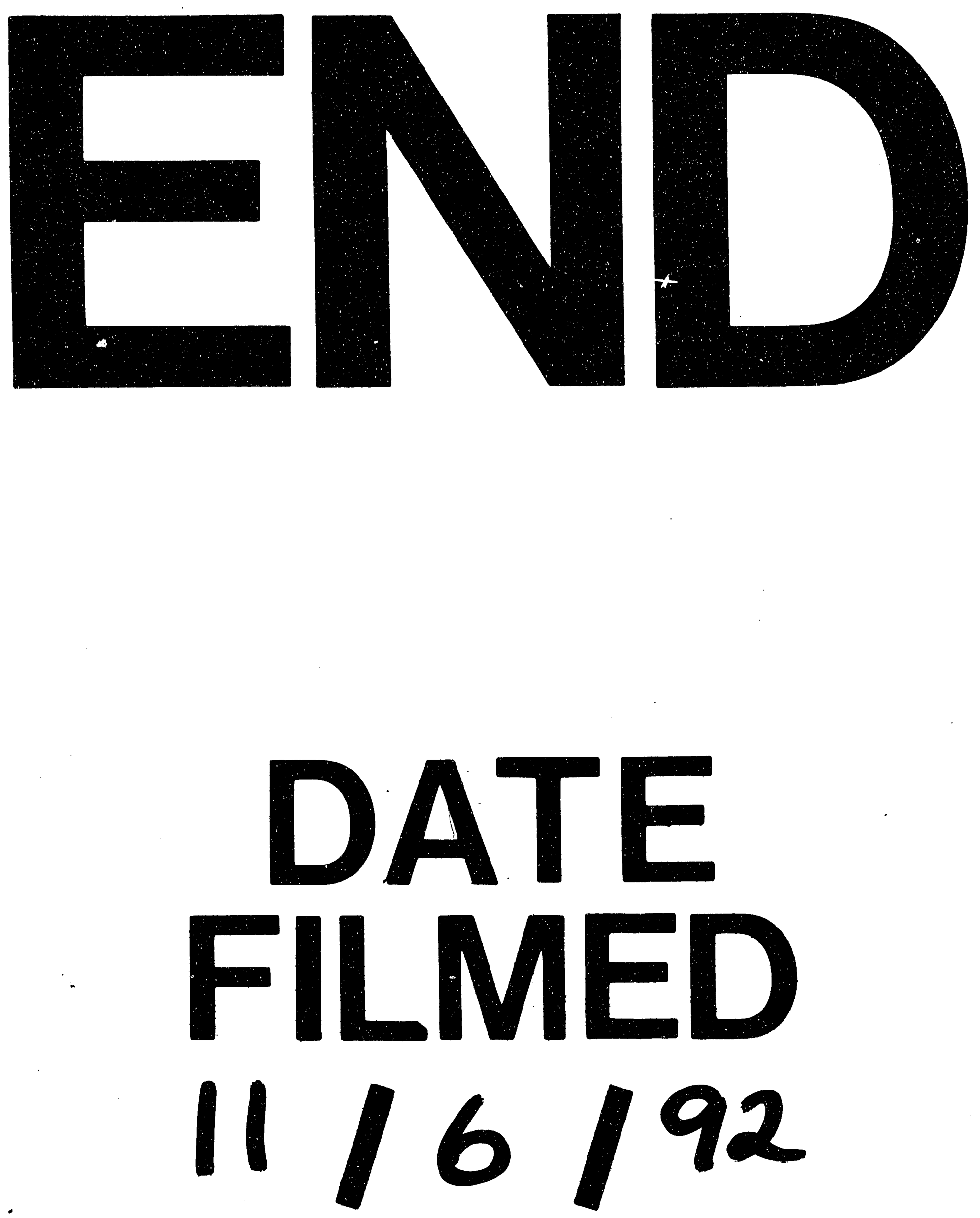

1 
